\title{
Colonization patterns of mobile cryptic animals into interstices of coral rubble
}

\author{
Y. Takada ${ }^{1,2, *}$, O. Abe $^{1}$, T. Shibuno ${ }^{1}$ \\ ${ }^{1}$ Ishigaki Tropical Station, Seikai National Fisheries Research Institute, Fukai-Ota 148-446, Ishigaki, Okinawa 907-0451, \\ Japan
}

${ }^{2}$ Present address: Japan Sea National Fisheries Research Institute, Suido-cho 1-5939-22, Niigata 951-8121, Japan

\begin{abstract}
Coral rubble is one of the characteristic bottom habitats in tropical and subtropical coral reefs. Many mobile organisms inhabit the interstices among coral rubble. Because coral rubble habitats are frequently subjected to physical disturbances, the process of assemblage recolonization is important for maintaining the diversity and productivity in coral reefs. The present study examined the colonization patterns of these mobile organisms by using experimental traps with defaunated coral rubble at 3 areas (Back reef, Seagrass bed, and Nearshore) in a fringing coral reef on Ishigaki Island, Japan. Sixteen mesh trays filled with coral rubble were set at each of the 3 areas; 4 trays were collected after 1, 2, 4, and $8 \mathrm{wk}$. The experiment was repeated in winter and spring. The number of species that occurred in the trays generally increased with the time period, but detailed examination was difficult because of significant interaction factors. Higher order interactions (season, area, and time period) were also significant for variations in assemblage composition. Temporal and spatial variations in abundances of 15 numerically dominant species (gastropods and decapods) were analyzed by a general linear model with an Akaike's information criterion model selection. Although the patterns of colonization were species specific, initial $(<1 \mathrm{wk})$ and time-dependent $(2$ to $8 \mathrm{wk})$ patterns were recognized. These results suggest that a short-distance movement within the local area is the main pathway for the colonization into a disturbed coral rubble habitat. Although seasonal variability in colonization requires consideration, the method using traps with coral rubble provides a standard habitat for quantitative assessment of the assemblage composition of cryptic organisms in coral reefs.
\end{abstract}

KEY WORDS: Coral rubble · Assemblages - Temporal variations - Patterns of colonization · AIC model selection

- Resale or republication not permitted without written consent of the publisher

\section{INTRODUCTION}

Coral rubble is one of the characteristic bottom habitats in tropical and subtropical coral lagoons, along with patches of microatolls, seagrass beds, and sandy bottoms. The small interstices among the coral rubble are utilized by small mobile organisms as permanent or transient habitats such as refuges from larger predators or areas for feeding on microalgae and on other smaller organisms. Although coral rubble habitats are recognized as an important component of the diversity (Preston \& Doherty 1990, 1994, Meesters et al. 1991,
Bouchet et al. 2002) and the productivity (Klumpp et al. 1988, Arias-González et al. 1997, Depczynski \& Bellwood 2003) of coral reefs, little attention has been paid to the maintenance of the diversity of assemblages in coral rubble (Peyrot-Clausade 1980, Choi 1984, Gischler \& Ginsburg 1996).

Coral rubble is created from the partial destruction and fragmentation of hermatypic corals and accumulated by currents and waves (Aronson \& Precht 1997, Yamano et al. 2000, Rasser \& Riegl 2002). Coral rubble habitats suffer frequent physical disturbances from various factors: for example, episodic typhoons and 
seasonal storms (Kobluk \& Lysenko 1993, Rogers 1993, Scoffin 1993), anchoring by ships (Dinsdale \& Harriott 2004), and feeding activity of fishes (Shibuno et al. 1994). Thus, colonization after these disturbances is an important process for the maintenance of species diversity in coral rubble habitats, but only a few studies have been carried out on this topic (PeyrotClausade 1980, Kobluk \& Lysenko 1993).

For benthic mobile organisms, colonization of cryptic habitats in the interstices of coral rubble may take less than a few weeks (Peyrot-Clausade 1980). Based on analogies with other cryptic marine systems, such as coral commensals (Castro 1978), epifauna of seagrasses (Edgar 1992), and interstices of intertidal boulders (Takada 1999), 3 pathways of colonization into coral rubble after a small-scale disturbance can be suggested (Fig. 1). The first pathway is colonization from a deeper layer of the coral rubble. The second pathway is colonization from adjacent undisturbed areas of the coral rubble. In this pathway, mobile organisms migrate by crawling on the surface or through the interstices of the coral rubble or by shortdistance swimming through the water column. The third pathway is colonization through the water column from distant source habitats. Recruitment from swimming larvae and nocturnal swimming activity of some benthic organisms (Jacoby \& Greenwood 1989, Saigusa 2001) are the main mechanisms of the third pathway. In practice, a single species of mobile organism may take more than one of these pathways.

In the present study, patterns of colonization into coral rubble were investigated experimentally by using mesh trays filled with coral rubble. Defaunated coral rubble was used as a standard microhabitat to compare the patterns of colonization between 3 typical areas of coral rubble habitats on the fringing reef of Ishigaki Island: the Back reef, surrounded by dead

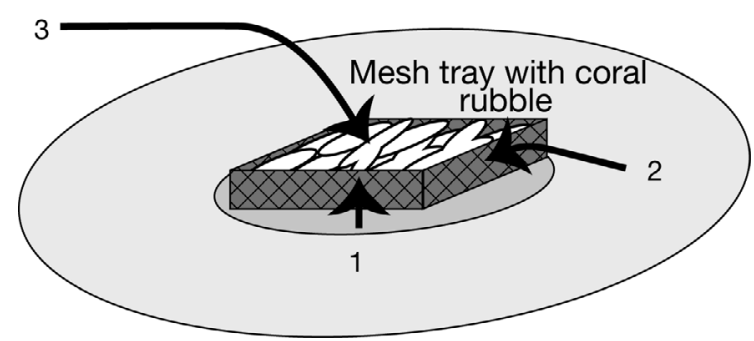

Fig. 1. Experimental mesh tray $(21.5 \times 17.5 \times 6.0 \mathrm{~cm})$ filled with defaunated coral rubble was designed to simulate a small-scale disturbance on the bottom habitats in a coral lagoon. There are 3 pathways to colonize the interstices of coral rubble in the mesh tray: (1) colonization from the substrate immediately below the mesh tray, (2) colonization from the adjacent area, and (3) colonization from distant habitats through the water column branching Acropora spp.; the Seagrass bed, with a mixture of scattered corals; and Nearshore, with patchy microatolls. The bottom substrates of the Seagrass and Nearshore areas were a mixture of sand and coral rubble. Temporal change of the abundance of the mobile animals that colonized into the coral rubble was examined by time-series sampling of the mesh trays. Because the physical structure of the microhabitat in the trays with coral rubble was the same, variations in the assemblage composition between the trays are affected by the colonization process, species pool for the colonization, and environmental factors. Supposing a simple case in which the source pool of colonizing individuals is constant over time, which would be expected in the third pathway, the number of colonized individuals would increase in a time-additive manner. On the other hand, if colonization is affected by the density of already colonized individuals in the tray, which would be expected in the second pathway, the number of colonized individuals would increase in a time-multiplicative manner. Although the assemblage composition in the mesh tray was determined by both colonization and emigration, we expected that the first pathway affects variations between the mesh trays within the area, the second pathway affects variations between the areas, and the third pathway acts as a common factor across the 3 areas.

The purposes of this study were (1) quantitative elucidation of the diversity and assemblage composition of mobile organisms in the interstices of coral rubble and (2) comparison of the colonization patterns between some of the abundant species. Factors controlling the colonization are discussed in relation to the colonization pathways. In addition, we evaluate a method of using mesh trays with coral rubble as a potential standard habitat for investigating the reef environment.

\section{MATERIALS AND METHODS}

Ishigaki Island is one of the Ryukyu Islands in southwestern Japan, and is surrounded by fringing coral reefs. On average, 1.9 typhoons per year approach Ishigaki Island (Yamano et al. 2000). After the mass coral-bleaching event in 1998, most of the corals around Ishigaki Island were dead (Fujioka 1999) and became coral rubble.

The experiment was carried out in a coastal lagoon of Urasoko Bay $\left(124^{\circ} 13^{\prime} \mathrm{N}, 24^{\circ} 27^{\prime} \mathrm{E}\right.$; Fig. 2) on the northern side of Ishigaki Island. The mean tidal range there is $1.7 \mathrm{~m}$ during spring tides. Seawater temperature ranges from 21 to $30^{\circ} \mathrm{C}$ (Fujioka 1999), and salinity ranges from 32 to $35 \mathrm{psu}$ (Takada et al. 2005). Three 

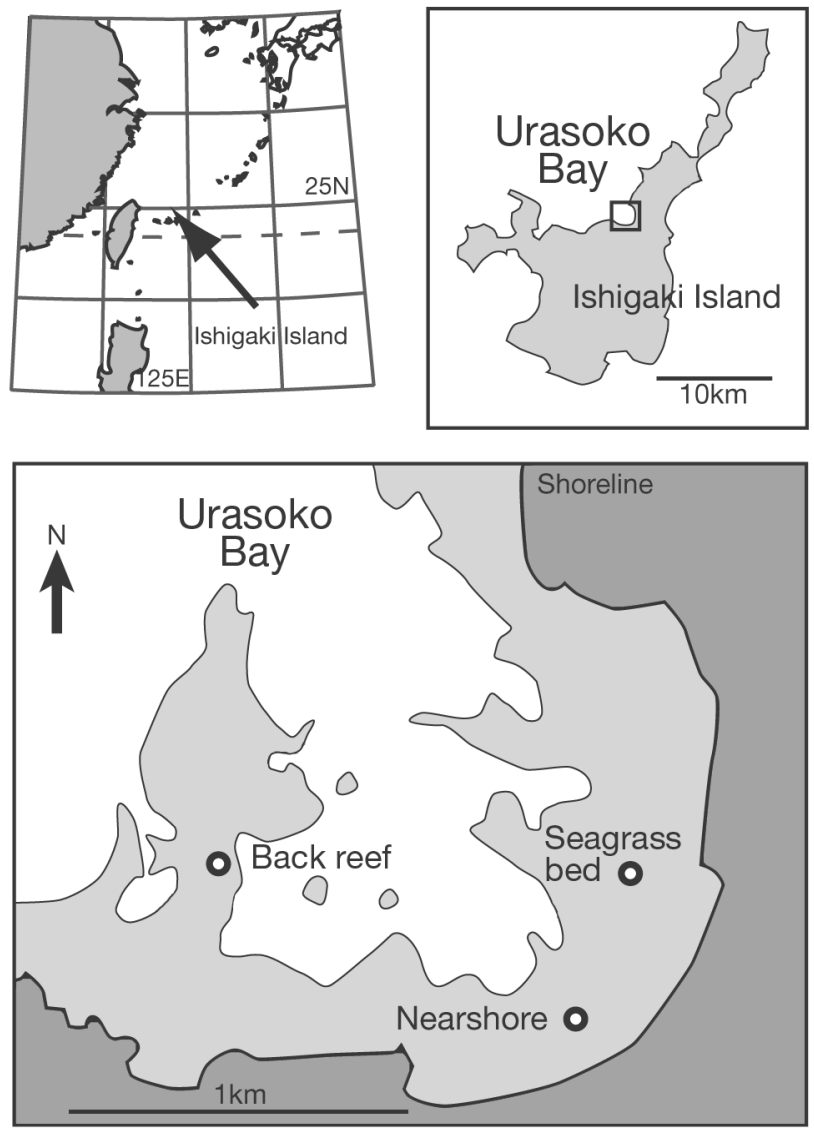

Fig. 2. Three study sites (Back reef, Seagrass bed, and Nearshore) in Urasoko Bay, northern side of Ishigaki Island, southwestern Japan. Thin lines in Urasoko Bay show the approximate $5 \mathrm{~m}$ depth contour line, judged from an aerial photograph (The Geological Survey Institute, Japan, 1995)

study sites were selected: Back reef $(1.5 \mathrm{~m}$ below the mean low water of spring tides), Seagrass bed $(0.8 \mathrm{~m})$, and Nearshore $(1.0 \mathrm{~m})$. At the Back reef, the bottom substrate consisted of coral rubble produced from adjacent patches of branching corals (mainly Acropora spp.; Fujioka 1998). The Seagrass bed was mainly formed by Thalassia hemprichii and Cymodocea rotundata (Takada \& Abe 2002), with a mixture of sand and coral rubble at the bottom. At the Nearshore area, bottoms of sand and coral rubble were spread among microatolls of Porites spp.

In order to quantitatively sample mobile animals living in the interstices of coral rubble, we used polyethylene mesh trays $(21.5 \times 17.5 \times 6.0 \mathrm{~cm}, 1.2 \mathrm{~mm}$ thick, with $6 \mathrm{~mm}$ mesh diameter; Ikeda) filled with coral rubble. Coral rubble was collected at the Back reef site. The coral rubble was formed of fragments of dead branching corals (mainly Acropora spp.) 3 to $15 \mathrm{~cm}$ in length and 0.5 to $1.5 \mathrm{~cm}$ in diameter. These fragments of coral rubble were dried and exposed to sun for $2 \mathrm{wk}$ to defaunate organisms on the rubble. Each mesh tray contained $1.0 \mathrm{~kg}$ (dry weight) of the coral rubble.

Sixteen mesh trays were set randomly within a circle of $10 \mathrm{~m}$ diameter in each of the 3 areas (Back reef, Seagrass bed, and Nearshore), and 4 trays were collected randomly after $1,2,4$, and $8 \mathrm{wk}$. The trays were placed on the bottom substrate without disturbing the bottom surface. Natural projections within the coral rubble hooked the mesh and anchored the tray to the bottom. The experiment was done in 2 seasons: winter (from November 1998 to February 1999) and spring (from April to June 2000). These 2 seasons were chosen to avoid the effects of typhoons because most typhoons occur during July to September. Thus, the experiment was designed with 3 fixed factors (2 seasons, 3 areas, and 4 periods), with each treatment having 4 replicate trays.

Samples were taken by enclosing each mesh tray in a plastic bag underwater. These samples were brought back to the laboratory within an hour and iced to immobilize the animals. The animals were extracted from the interstices and the surface of the coral rubble by washing with iced freshwater. All the contents of the plastic bag and the washed water were poured into a $0.125 \mathrm{~mm}$ sieve before sorting as follows. Larger mobile animals (molluscs, echinoderms, fishes, decapod and stomatopod crustaceans) were sorted by naked eye, and the number of individuals counted to the lowest possible taxonomic level by aid of a binocular microscope. Larvae of the larger animals, smaller mobile animals (i.e. polychaetes, gammarids, isopods, and tanaids), and other microscopic animals (i.e. foraminifera, nematodes, copepods, and ostracods) were also retained on the sieve. But because of difficulties related to identification, they were not included in the following analyses.

The numbers of species that occurred in the traps were compared using a 3-factor ANOVA (season, period, and area). Homogeneity of variances was confirmed by Bartlett's test $(\mathrm{p}>0.05)$. The assemblage compositions were analyzed by following standard multivariate techniques (Legendre \& Legendre 1998). Abundance data were transformed by $\log _{10}(x+1)$ to downweight effects of the numerically dominant species and compiled into a square matrix (species $\times$ trays). This species-by-tray matrix was converted into a triangular tray-by-tray similarity matrix by calculating the coefficient of Steinhaus (Bray-Curtis coefficient) between all tray pairs. Ordinations in reduced spaces were generated by nonmetric multidimensional scaling (nMDS) based on the tray-by-tray similarity matrix. Effects of the 3 factors (season, period, and area) on the assemblage composition were tested by using PERMANOVA (Anderson 2001) based on a dissimilarity $(\boldsymbol{D}=1-\boldsymbol{S})$ matrix derived from the tray-by- 
tray similarity $(\boldsymbol{S})$ matrix. Permutation p-values were estimated by 4999 iterations of the unrestricted permutation of the raw data.

Species that occurred with a frequency of $>1$ individual per trap on average were regarded as abundant species (15 species). Association of occurrence between the abundant species was examined. A species-by-species similarity matrix was calculated by using the coefficient of chi-squared similarity between the 15 species pairs based on a part of the species-bytray matrix. A hierarchical cluster analysis, using Ward's minimum variance method, identified groups of species that had similar abundance distributions among trays. An ordination of the 15 species was generated by nMDS.

In order to explain the colonization patterns of the 15 abundant species, a general linear model (GLM) was constructed. In this GLM, season (winter and spring) and area (Back reef, Seagrass bed, and Nearshore) were the fixed factors, and period $(1,2,4$, and $8 \mathrm{wk}$ ) was treated as both linear and log-linear covariates. The full model was:

$$
\begin{aligned}
& Y=b_{1}+b_{2} \cdot \mathrm{A}+b_{3} \cdot \mathrm{S}+b_{4} \cdot \mathrm{A} \cdot \mathrm{S}+\mathrm{P} \cdot\left(b_{5}+b_{6} \cdot \mathrm{A}+b_{7} \cdot \mathrm{S}\right. \\
& \left.+b_{8} \cdot \mathrm{A} \cdot \mathrm{S}\right)+\mathrm{LP} \cdot\left(b_{9}+b_{10} \cdot \mathrm{A}+b_{11} \cdot \mathrm{S}+b_{12} \cdot \mathrm{A} \cdot \mathrm{S}\right)+e
\end{aligned}
$$

where $Y$ is the $\log$-transformed $\left[\log _{10}(x+1)\right]$ number of individuals, $b_{1}$ to $b_{12}$ are the parameters, $\mathrm{A}$ is area, $\mathrm{S}$ is season, $\mathrm{P}$ is period, LP is the $\log _{10}$ (period), and $e$ is error. Because the dependent variable $(Y)$ was logtransformed, the term $\mathrm{P}$ was a time-multiplicative factor and the term LP was a time-additive factor. In the parameter estimation of this GLM, each tray was treated as an independent sample, so the number of samples was 96 (3 areas, 2 seasons, 4 periods, and 4 replicate trays). Considering the hierarchy of the interaction terms, reduced models were constructed by alternatively taking out/putting in each factor of the full model. Then the best fit model for each species was determined by AIC (Akaike's information criterion) among the full model and all the reduced models. The AICs were calculated as AIC $=-2 L+2 K$, where $L$ was the maximized log likelihood and $K$ was the number of parameters in the model. The analyses of nMDS, cluster, GLM, and ANOVA were carried out using the software package Systat Version 7.01 (Systat Software).

\section{RESULTS}

During the study, 202 species of mobile animals, including 67 species of decapods and 105 species of gastropods, colonized the trays. Among these, 124 species occurred at the Back reef area, 93 species at the Seagrass bed area, and 91 species at the Nearshore area. Only 29 species were observed at all 3 areas.
The cumulative number of species at the 3 areas increased steadily over the study period in the winter and the spring and was much larger than the mean number of species in the trays (Fig. 3). Generally, the mean number of species in the trays was larger at the Back reef area than at the Seagrass bed and Nearshore areas, and it increased along with the period (Fig. 3). The results of the 3-way ANOVA (Table 1) showed that the number of species varied significantly $(p<0.05)$
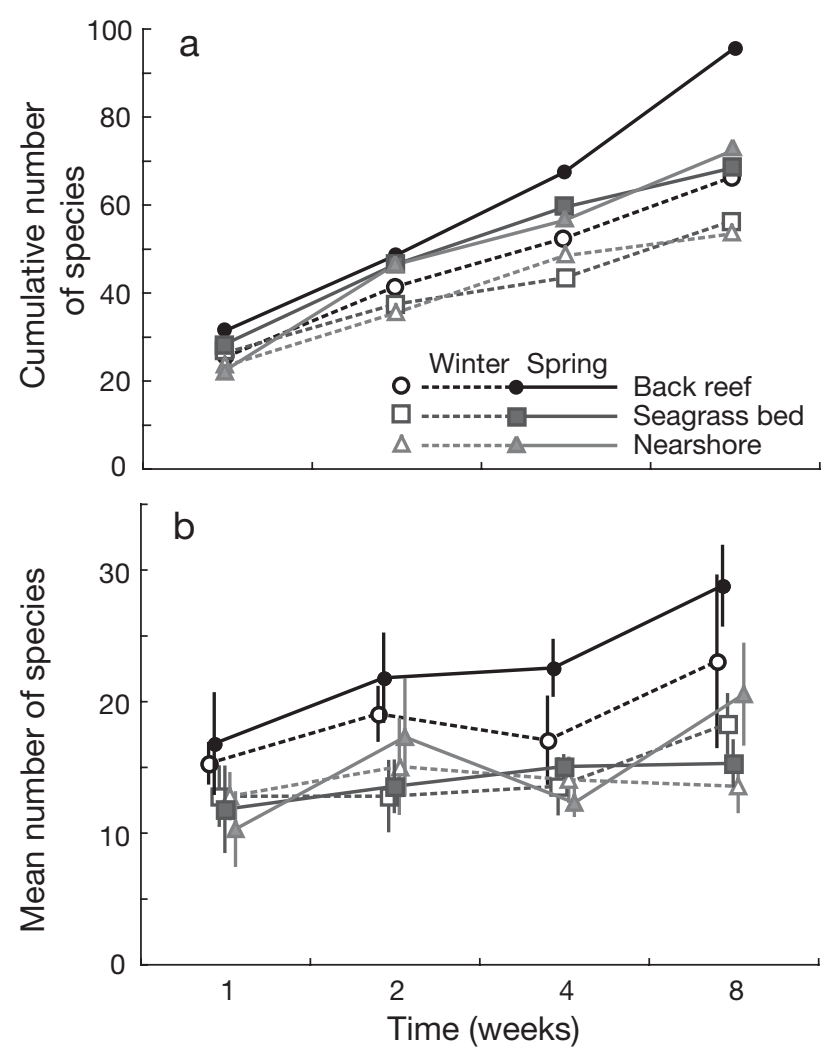

Fig. 3. Temporal patterns of (a) cumulative number of species and (b) mean number of species $( \pm \mathrm{SD}, \mathrm{n}=4)$ that colonized into the mesh trays

Table 1. Results of the 3-way ANOVA of the number of species in the mesh tray filled with coral rubble. Fixed factors were season (winter and spring), period (1, 2, 4, and $8 \mathrm{wk}$ ), and area (Back reef, Seagrass bed, and Nearshore)

\begin{tabular}{|lccccr|}
\hline Source & df & SS & MS & $F$ & $p$ \\
\hline Season (S) & 1 & 54.000 & 54.000 & 6.480 & 0.0131 \\
Period (P) & 3 & 538.708 & 179.569 & 21.548 & $<0.0001$ \\
Area (A) & 2 & 806.313 & 403.156 & 48.379 & $<0.0001$ \\
S $\times$ P & 3 & 47.083 & 15.694 & 1.883 & 0.1400 \\
S A & 2 & 68.812 & 34.406 & 4.129 & 0.0201 \\
$\mathrm{P} \times$ A & 6 & 110.104 & 18.351 & 2.202 & 0.0525 \\
S $\times$ P A & 6 & 121.604 & 20.267 & 2.432 & 0.0338 \\
Residual & 72 & 600.000 & 8.333 & & \\
\hline
\end{tabular}


with season, area, period, and their interactions, except the season $\times$ period and period $\times$ area interactions.

Results of PERMANOVA (Table 2) showed that all factors (season, period, area, and their interactions) were significant $(p<0.05)$ for the assemblage compositions (202 species by 96 trays). Ordination of nMDS (Fig. 4) supported the results of the PERMANOVA and indicated that the season and area factors were of primary importance. Points showing assemblage composition in the tray at the Nearshore area were positioned intermediate between the Back reef and the Seagrass bed (Fig. 4). Points for the Back reef area showed a shift to the bottom left corner of the figure with the increase of period.

In the present study, abundant species are defined as species that occurred at counts of $>1$ individual per trap on average. Fifteen species were recognized as abundant species. They accounted for $82.4 \%$ of the total number of individuals (8496 individuals). The proportion of the abundant species showed similar values among the 3 areas: $84.9 \%$ at the Back reef (within 4181 individuals), 79.6\% at the Seagrass bed (2255 individuals), and $80.5 \%$ at the Nearshore (2060 individuals). On the other hand, 80 species were recorded with only 1 individual over the whole study. Among these rare species, 44 species occurred at the Back reef, followed by 22 species at the Seagrass bed, and 14 species at the Nearshore.

The 15 abundant species were categorized into 3 groups by cluster analysis: Group 1 (7 species): Galathea mauritiana (= affinis), Pagurixus nanus, Zafra troglodytes, Cerithium stigmosum, Pusillina marmorata, Diala albugo, and Chlorodiella barbata; Group 2 (6 species): Coralliogalathea humilis, Thor paschalis, Periclimenes sp., Athanas djiboutensis, Periclimenella spinifera, and Pagurixus sp.; and Group 3 (2 species): Diogenes pallescens and Thalamita integra. Superimposing the 3 groups of the clustered species on a nMDS

Table 2. Results of the PERMANOVA on the basis of Steinhaus (Bray-Curtis) dissimilarities for assemblages in the mesh tray (202 species) after $\log _{10}(x+1)$ transformation. Fixed factors were season (winter and spring), period (1,2, 4, and $8 \mathrm{wk}$ ), and area (Back reef, Seagrass bed, and Nearshore)

\begin{tabular}{|lcccc|}
\hline Source & df & SS & $F$ & p (permutation) \\
\hline Season (S) & 1 & 1.4927 & 16.9580 & 0.0002 \\
Period (P) & 3 & 0.7673 & 2.9059 & 0.0002 \\
Area (A) & 2 & 6.0187 & 34.1888 & 0.0002 \\
$\mathrm{~S} \times \mathrm{P}$ & 3 & 0.6896 & 2.6114 & 0.0002 \\
$\mathrm{~S} \times \mathrm{A}$ & 2 & 0.7197 & 4.0880 & 0.0002 \\
$\mathrm{P} \times \mathrm{A}$ & 6 & 1.0612 & 2.0094 & 0.0002 \\
$\mathrm{~S} \times \mathrm{P} \times \mathrm{A}$ & 6 & 0.7705 & 1.4589 & 0.0276 \\
Residual & 72 & 6.3375 & & \\
\hline
\end{tabular}

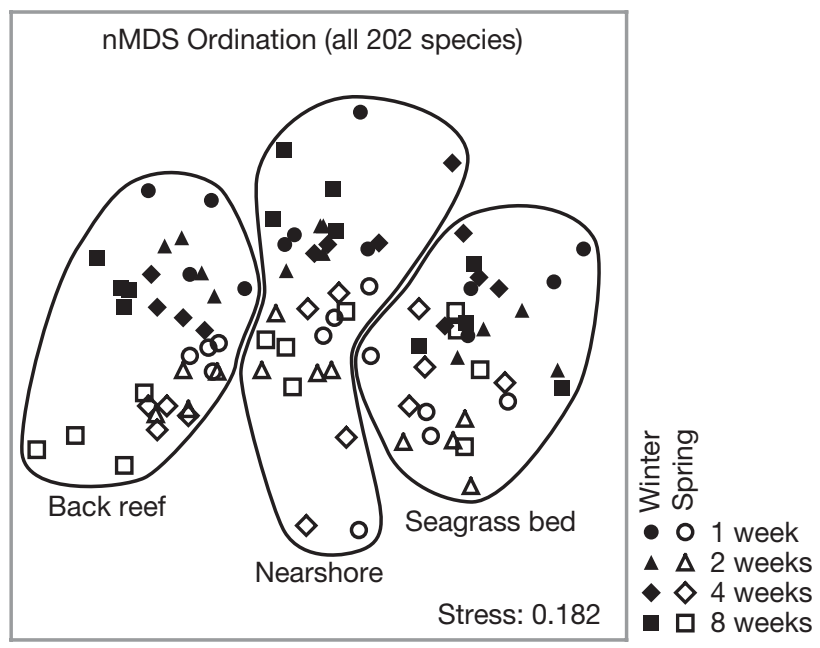

Fig. 4. Nonmetric multidimensional scaling (nMDS) plot of the assemblages colonized into each mesh tray on the basis of Steinhaus (Bray-Curtis) similarities after $\log _{10}(x+1)$ transformation. The points for the 3 areas are shown

ordination plot (Fig. 5) showed that the Group 2 species were positioned between Groups 1 and 3. Speciesspecific patterns of abundance suggested that the result of the cluster analysis demonstrated mainly the spatial variations: Group 1 species mainly occurred at the Back reef (Fig. 6), Group 2 species occurred in all 3 areas (Fig. 7), while Group 3 species mainly occurred at the Seagrass bed (Fig. 8).

Application of the GLM model selection revealed species-specific patterns of the variation (Figs. 6 to 8 , Table 3). In all the species, the selected GLM models included positive overall constant $\left(b_{1}>0\right)$. This indicates that in most cases some individuals were observed in the traps at $1 \mathrm{wk}$ (Figs. 6 to 8 ) and that some individuals colonized the traps almost immedi-

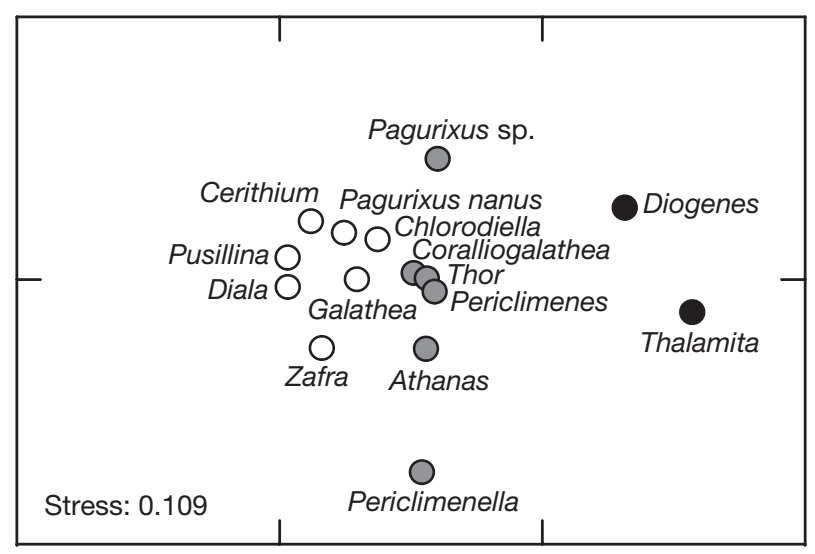

Fig. 5. Nonmetric multidimensional scaling (nMDS) plot of the 15 abundant species on the basis of chi-squared similarities. Results of the cluster analysis are also shown: $\mathrm{O}=$ Group 1, $\bullet=$ Group $2, \bullet=$ Group 3 . For full species names see Table 3 


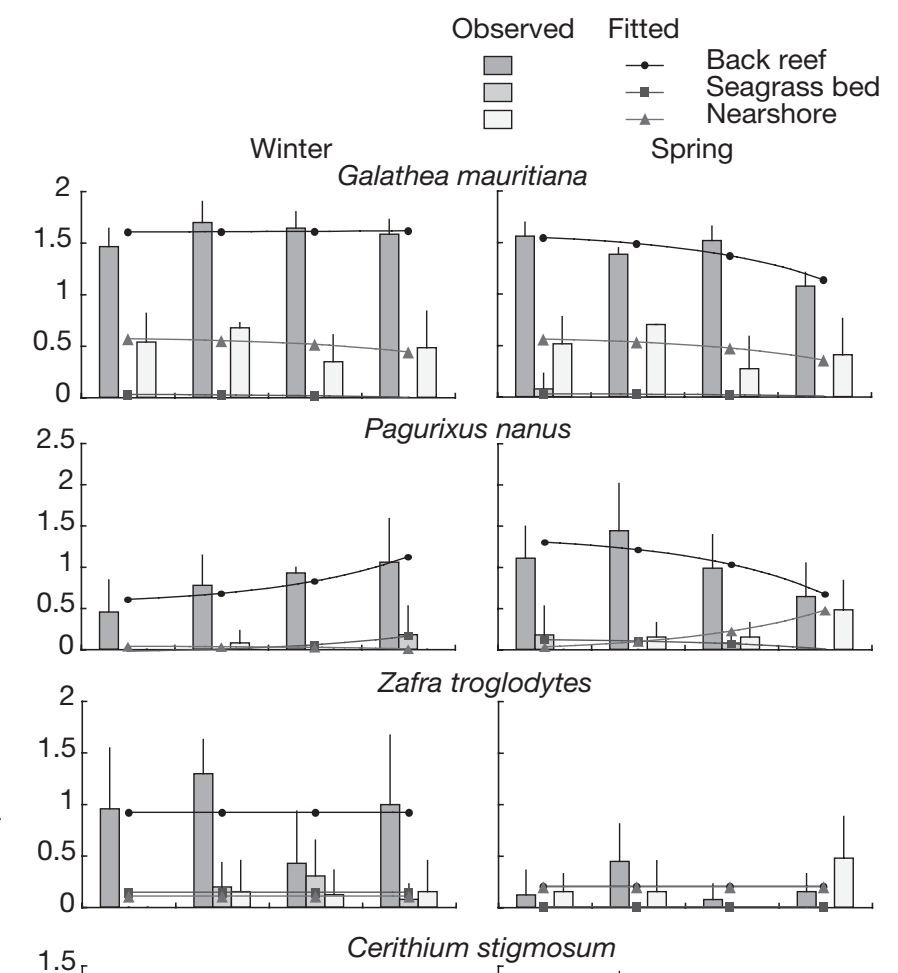

ately after the traps were set. Results of the GLM (Table 3) showed that the selected model of all the species included the area factor. Zafra troglodytes and Pagurixus sp. lacked the factors Period and $\log$ (period), and their higher interactions. The estimated number of individuals (Figs. $6 \& 7$ ) of these 2 species did not change temporally.

In the other 13 species, the number of individuals in the trays showed a temporal increase or decrease, and these patterns were species specific. Diogenes pallescens, Periclimenella spinifera, and Diala albugo included the factor $\log$ (period), but not the factor period, so the estimated number of individuals showed a linear increase or decrease (Figs. 6 to 8). In particular, $D$. albugo lacked the factor season and its higher interactions, so the estimated patterns of colonization of $D$. albugo were the same between winter and spring (Fig. 6).

The other 10 species that included the period factor showed concave or convex changes during the $8 \mathrm{wk}$ of the study. Among these, 5 species (Coralliogalathea humilis, Thor paschalis, Athanas djiboutensis, Thalamita integra, and Chlorodiella barbata) included both the timemultiplicative (period) and the time-additive [log(period)] factors. However, no species included both of the 3-way interaction factors $(\mathrm{LP} \times \mathrm{A} \times \mathrm{S}$ and $\mathrm{P} \times \mathrm{A} \times \mathrm{S})$.

\section{DISCUSSION}

This study demonstrated the rich diversity of the cryptic assemblage of large mobile animals in the interstices of coral rubble. Decapods and gastropods were the major components of the assemblage. The experiment using mesh trays with coral rubble showed that the assemblage composition varied with season, local habitat, and the period of time that the tray was set. Species-specific colonization patterns became apparent by the detailed analysis of the 15 abundant species. Smaller animals, including polychaetes, peracarid crustaceans, and copepods, were also numerous, but were not investigated in this study.

Rich diversity of cryptic gastropods was also recognized in the coral reef of New Caledonia (Bouchet et al. 2002). Bouchet et al. (2002) surveyed various habitats, from mangroves to the outer slope of the reef and demonstrated that (1) $80 \%$ of molluscan species were gastropods, (2) $52 \%$ of the species were $<8.8 \mathrm{~mm}$ in size, 


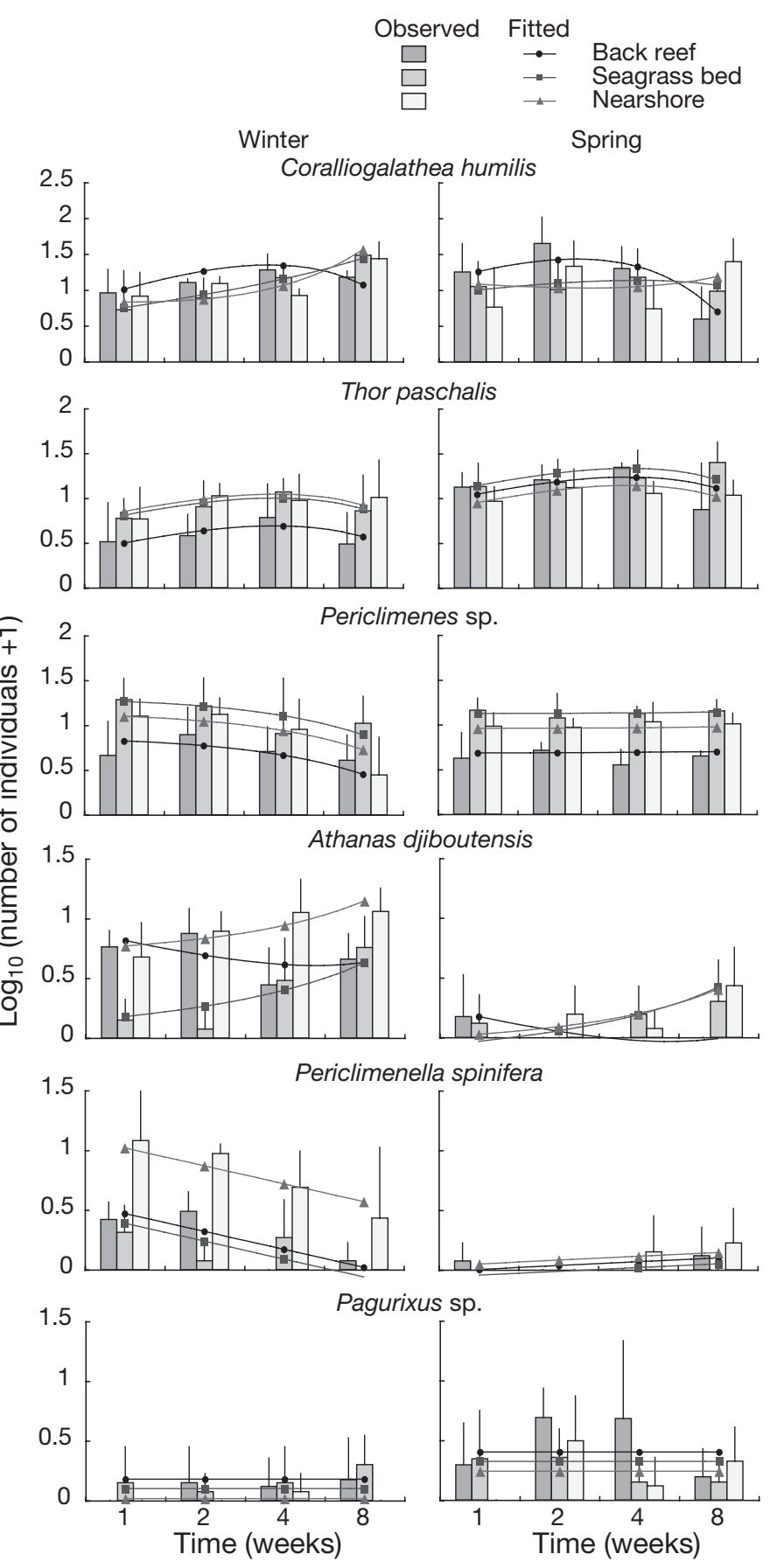

Fig. 7. Temporal patterns of the number of individuals of the 6 abundant species in Group 2 (see Fig. 5). Other details are as described in Fig. 6

and (3) $20 \%$ of the species were represented by single specimens. The present study examined assemblages that colonized coral rubble habitats and shows similar results: more than half of the mobile cryptic species were gastropods and $40 \%$ of the species were recorded as single specimens. Although the present study did not analyze the size of cryptic species, the maximum shell length of abundant gastropods (Zafra troglodytes, Cerithium stigmosum, Pusillina marmorata, and Diala albugo) was <10 mm.

Assemblage composition and abundance of cryptic benthic organisms have been shown to be affected by the habitat structure (e.g. Coles 1980, Takada 1999). However, in this study, variations in the habitat structure between the experimental coral rubble substrate used in the trays were controlled. Thus, the differences between the 3 areas (Back reef, Seagrass bed, and Nearshore) were due to the differences of potential colonizers (species pools) and the mechanisms of colonization in the 3 areas.

\section{Patterns of colonization}

Colonization through the first and second pathways (Fig. 1) is related to the local species pools that are assumed to differ among the 3 areas (Back reef, Seagrass bed, and Nearshore). The first pathway of colonization is migration from the layer of coral rubble that was covered by the mesh tray. Individuals of mobile organisms that inhabit the interstices of coral rubble are thought to respond to the addition of the mesh tray above their habitat, and migrate upward about $6 \mathrm{~cm}$ into the mesh tray to keep their relative position from the surface layer in the rubble. The colonization through the first pathway would occur initially $(<1 \mathrm{wk})$ by all mobile species, irrespective of their mobility. The assemblage compositions in the mesh trays were different across the areas after $1 \mathrm{wk}$ (Fig. 4). Thus, the first pathway is concluded to have substantially contributed to the initial composition of the assemblages and the differences among the 3 areas. The large number of species at the Back reef in the mesh trays after $1 \mathrm{wk}$ (Fig. 3) suggested that species involved in the first pathway of colonization at the Back reef were more diverse than at the other areas.

Colonization through the second pathway is thought to occur intermittently or continuously over the experimental period. Individuals involved in the second pathway were colonized from habitats surrounding the mesh tray. The steady increase of the cumulative number of species in all 3 areas (Fig. 3) indicated that potential species pools for colonization were larger than those actually observed in the experimental mesh tray. Differences among the 3 areas indicated that the local diversity of the species pool was larger at the Back reef area than at the Seagrass bed and Nearshore areas. This finding 


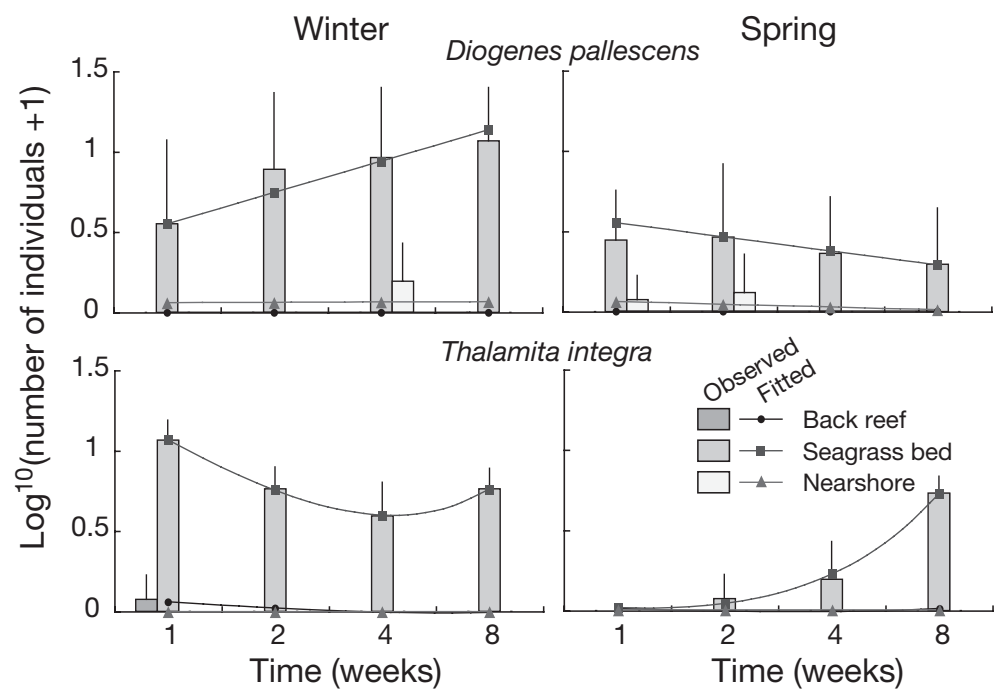

Fig. 8. Temporal patterns of the number of individuals of the 2 abundant species in Group 3 (see Fig. 5). Other details are as described in Fig. 6 all 3 areas, the results of the cluster analysis and the nMDS ordination showed that the 15 abundant species were categorized into 3 groups by their patterns of colonization. In addition, the GLM model selection by the AIC (Table 3) demonstrated species-specific temporal and spatial patterns of colonization in detail. All the abundant species included the area factor. The model of this study treated temporal variations separately as 2 factors: time-additive and time-multiplicative factors (LP and $\mathrm{P}$ in Table 3, respectively). Five species (Coralliogalathea humilis, Thor paschalis, Athanas djiboutensis, Thalamita integra, and Chlorodiella barbata) simultaneously included both timeadditive and time-multiplicative factors that a classical factorial ANOVA was unable to detect.

Peyrot-Clausade (1980) briefly deis also supported by the results of nMDS; the assemblage composition at the Back reef area became more divergent from the other areas by period (Fig. 4). Among the 202 species observed in the experiment, only 29 species $(14.4 \%)$ were common to all 3 areas. Thus, the local species pools differed greatly across the areas. Part of this difference was due to the rare gastropod species that were recorded with only 1 individual during the study period.

Abundant species also contributed to the variation of species composition across the areas. Although 11 abundant species (among the 15 species) occurred in scribed a schematic pattern of colonization by cryptic animals on fragments of branched corals (Acropora sp.) enclosed in a mesh bag: mass colonization of small crustaceans (amphipods, isopods, and tanaids) during the first $2 \mathrm{wk}$, followed by colonization of larger organisms (especially galatheid anomurans) wthin 2 to $5 \mathrm{wk}$, and then establishment of sedentary assemblages (mainly polycheates) from $5 \mathrm{wk}$ to $7 \mathrm{mo}$. In the present study, 2 species of galatheid anomurans (Coralliogalathea humilis and Galathea mauritiana) occurred abundantly (Figs. 6 \& 7). At the Back reef area, both species showed a maximum abundance during Weeks

Table 3. Summary of the general linear model for the number of individuals [ $\log _{10}(x+1)$ transformed] of the 15 abundant species in the mesh trays. Factors with ' + ' for each species were included in the best fit model determined by Akaike's information criterion. Time-independent, time-additive (including LP), and time-multiplicative (including P) factors were designated. Species are listed in order of decreasing abundances. Decapod crustaceans: C = Caridea, D = Diogenidae, $G=$ Galatheidae, $\mathrm{B}=$ Brachyura; gastropods: $\mathrm{M}=$ molluscs

\begin{tabular}{|c|c|c|c|c|c|c|c|c|c|c|c|c|}
\hline Species & $\begin{array}{l}\text { Taxon } \\
\text { group }\end{array}$ & $\begin{array}{l}\text { Area } \\
\text { (A) }\end{array}$ & $\begin{array}{c}\text { Season } \\
\text { (S) }\end{array}$ & $\mathrm{A} \times \mathrm{S}$ & LP & $\mathrm{LP} \times \mathrm{A}$ & $\mathrm{LP} \times \mathrm{S}$ & $\begin{array}{c}\mathrm{LP} \times \\
\mathrm{A} \times \mathrm{S}\end{array}$ & $\begin{array}{c}\text { Period } \\
\text { (P) }\end{array}$ & $\mathrm{P} \times \mathrm{A}$ & $\mathrm{P} \times \mathrm{S}$ & $\begin{array}{r}\mathrm{P} \times \\
\mathrm{A} \times \mathrm{S}\end{array}$ \\
\hline Coralliogalathea humilis & $s \quad \mathrm{G}$ & + & + & & + & + & & & + & + & + & \\
\hline Galathea mauritiana & G & + & & & & & & & + & + & + & + \\
\hline Thor paschalis & $\mathrm{C}$ & + & + & + & + & & & & + & & & \\
\hline Periclimenes sp. & $\mathrm{C}$ & + & + & & & & & & + & & + & \\
\hline Pagurixus nanus & $\mathrm{D}$ & + & + & + & & & & & + & + & + & + \\
\hline Athanas djiboutensis & $\mathrm{C}$ & + & + & + & + & + & & & + & & & \\
\hline Zafra troglodytes & M & + & + & + & & & & & & & & \\
\hline Diogenes pallescens & $\mathrm{D}$ & + & & & + & + & + & + & & & & \\
\hline Cerithium stigmosum & M & + & + & + & & & & & + & + & + & + \\
\hline Periclimenella spinifera & $\mathrm{C}$ & + & + & + & + & & + & & & & & \\
\hline Pusillina marmorata & M & + & & & & & & & + & & + & \\
\hline Diala albugo & $\mathrm{M}$ & + & & & + & + & & & & & & \\
\hline Pagurixus sp. & $\mathrm{D}$ & + & + & & & & & & & & & \\
\hline Thalamita integra & $\mathrm{B}$ & + & + & + & + & + & + & + & + & + & & \\
\hline Chlorodiella barbata & B & + & + & & + & + & + & + & + & + & & \\
\hline
\end{tabular}


1 to 4 and decreased slightly at $8 \mathrm{wk}$, as observed in an experiment in Madagascar (Peyrot-Clausade 1980). But $C$. humilis at the Nearshore area showed a slightly increasing trend during the experimental period (Fig. 7).

We supposed that the third pathway of colonization would act as a common factor for all 3 areas. Opportunity for colonization from a species pool of swimming larvae and adults through the water column was thought to be the same among the 3 areas because Urasoko Bay is small $(<1.5 \mathrm{~km})$ and it is assumed that tidal- and wind-driven currents within the bay (Takada et al. 2005) mix the water masses between the areas. We expected there would be species with the same colonization patterns across the 3 areas due to the common temporal events of recruitment from swimming larvae or adults in the 3 areas. Such species should show significant period factors (LP or P), with insignificant interaction factors between period and area $(\mathrm{LP} \times \mathrm{A}$ or $\mathrm{P} \times \mathrm{A})$. As the results show (Table 3$)$, Thor paschalis, Periclimenes sp., and Pusillina marmorata were the candidates among the 15 abundant species. But these 3 species showed a temporal decrease in number that implied escape from or death in the tray instead of colonization. Therefore, the results did not detect any evidence of a third pathway that acts commonly across the 3 areas.

Small-scale variations were observed in zooplankton in coral reefs (Alldredge \& King 1977, Jacoby \& Greenwood 1989) and in the colonization of sessile organisms through planktonic larvae (e.g. Wahl 2001). Lack of common temporal patterns may be explained by local variation in colonization through the water column within a $<1 \mathrm{~km}$ scale and other local factors. Sediments deposited on the surface of the coral rubble may produce local variations in habitat quality (Takada et al. unpubl. data). Predation and competitive interactions between the colonized individuals may produce an underestimation of the colonization in the coral rubble. In a future experiment, using a fish exclusion cage around the tray may help evaluate the role of predation.

\section{Implications for coral reef monitoring}

In this study, using experimental trays made quantitative comparison of the assemblage composition possible. The rapid colonization of mobile organisms into the trays over periods of 2 to $4 \mathrm{wk}$ can be used to examine the variations reflected by the surrounding environment. Gischler (1997) stated that assemblage of sessile organisms on coral rubble was not a good indicator for the reef environment because the development of the assemblage takes a long period: 6 mo
(Gischler 1997) or 3 yr (Choi 1984). By analyzing the assemblage of mobile organisms instead of sessile organisms, coral rubble in mesh trays can be used as a method for standardizing the habitat for environmental monitoring. In addition, this method can be carried out without destruction of natural habitats. Dead coral heads provide a cryptic habitat for mobile organisms similar to coral rubble, but the assemblage composition is related to the surface area of the dead coral (Coles 1980), which is difficult to control without the physical destruction of the coral skeletons.

After the mass bleaching event of corals in 1998 around Ishigaki Island, all the corals died out in some areas, and monitoring programs based on live corals became less informative. Assemblages in coral rubble are candidate indicators for additional monitoring programs that complement those of live corals. In practice, however, care should be taken regarding the seasonal variations in assemblage composition. Some of the abundant species, especially Athanas djiboutensis, Zafra troglodytes, and Periclimenella spinifera, also showed seasonal changes. Seasonal change in abundance and assemblage composition affects the trophic potentials of these cryptic organisms (Klumpp et al. 1988) and improves estimates of trophic models in coral reef ecosystems (e.g. Arias-González et al. 1997).

In conclusion, this study demonstrated a high diversity of mobile cryptic organisms in the interstices of the coral rubble habitat. The method using traps with coral rubble provided a standardizable habitat for quantitative assessment of mobile cryptic organisms in coral lagoons. Patterns of colonization were locally and seasonally variable as well as species-specific. This suggests that short-distance movement is the main pathway of colonization into coral rubble habitats after disturbance.

Acknowledgements. We thank K. Hashimoto, M. Kobayashi, and R. Oi for field and laboratory assistance. Taxonomic experts kindly assisted in identification of some of the specimens: K. Nomura (Caridea), T. Komai (Diogenidae), M. Osawa (Galatheidae), M. Takeda (Xanthidae), and K. Hasegawa (Gastropoda). Permission to work in the coral reef on Ishigaki Island was granted by the government of Okinawa Prefecture, Japan. This study was partly supported by GERF (F-5), the Ministry of the Environment of Japan.

\section{LITERATURE CITED}

Alldredge AL, King JM (1997) Distribution, abundance, and substrate preferences of demersal reef zooplankton at Lizard Island Lagoon, Great Barrier Reef. Mar Biol 41: 317-333

Anderson MJ (2001) A new method for non-parametric multivariate analysis of variance. Austral Ecol 26:32-46 
Arias-González JE, Delesalle B, Salvat B, Galzin R (1997) Trophic functioning of the Tiahura reef sector, Moorea Island, French Polynesia. Coral Reefs 16:231-246

Aronson RB, Precht WF (1997) Stasis, biological disturbance, and community structure of a Holocene coral reef. Paleobiology 23:326-346

Bouchet P, Lozouet P, Maestrati P, Heros V (2002) Assessing the magnitude of species richness in tropical marine environments: exceptionally high numbers of molluscs at a New Caledonia site. Biol J Linn Soc 75:421-436

Castro P (1978) Movements between coral colonies in Trapezia ferruginea (Crustacea: Brachyura), an obligate symbiont of scleractinian corals. Mar Biol 46:237-245

Choi DR (1984) Ecological succession of reef cavity-dwellers (coelobites) in coral rubble. Bull Mar Sci 35:72-79

Coles SL (1980) Species diversity of decapods associated with living and dead reef coral Pocillopora meandrina. Mar Ecol Prog Ser 2:281-291

Depczynski M, Bellwood DR (2003) The role of cryptobenthic reef fishes in coral reef trophodynamics. Mar Ecol Prog Ser 256:183-191

Dinsdale EA, Harriott VJ (2004) Assessing anchor damage on coral reefs: a case study in selection of environmental indicators. Environ Manage 33:126-139

Edgar GJ (1992) Patterns of colonization of mobile epifauna in a Western Australian seagrass bed. J Exp Mar Biol Ecol 157:225-246

Fujioka Y (1998) Checklist of the hermatypic corals of Urasoko Bay, Ishigaki Island, southwestern Japan. Bull Nansei Natl Fish Res Inst 31:1-11

Fujioka Y (1999) Mass destruction of the hermatypic corals during a bleaching event in Ishigaki Island, southwestern Japan. Galaxea 1:41-50

Gischler E (1997) Cavity dwellers (coelobites) beneath coral rubble in the Florida reef tract. Bull Mar Sci 61: 467-484

Gischler E, Ginsburg RN (1996) Cavity dwellers (coelobites) under coral rubble in southern Belize barrier and atoll reefs. Bull Mar Sci 58:570-589

Jacoby CA, Greenwood JG (1989) Emergent zooplankton in Moreton Bay, Queensland, Australia: seasonal, lunar, and diel patterns in emergence and distribution with respect to substrata. Mar Ecol Prog Ser 51:131-154

Klumpp DW, McKinnon AD, Mundy CN (1988) Motile cryptofauna of a coral reef: abundance, distribution and trophic potential. Mar Ecol Prog Ser 45:95-108

Kobluk DR, Lysenko MA (1993) Hurricane effects on shallowwater cryptic reef molluscs, Fiji Islands. J Paleontol 67:

Editorial responsibility: Howard Browman (Associate Editorin-Chief), Storebø, Norway
$798-816$

Legendre P, Legendre L (1998) Numerical ecology, 2nd English edn. Elsevier, Amsterdam

Meesters E, Knijn R, Willemsen P, Pennartz R, Roebers G, van Soest RWM (1991) Sub-rubble communities of Curaçao and Bonaire coral reefs. Coral Reefs 10:189-197

Peyrot-Clausade M (1980) Motile cryptofauna of Tuléar reef flats. Mar Biol 59:43-47

Preston NP, Doherty PJ (1990) Cross-shelf patterns in the community structure of coral-dwelling Crustacea in the central region of the Great Barrier Reef. I. Agile shrimps. Mar Ecol Prog Ser 66:47-61

Preston NP, Doherty PJ (1994) Cross-shelf patterns in the community structure of coral-dwelling Crustacea in the central region of the Great Barrier Reef. II. Cryptofauna. Mar Ecol Prog Ser 104:27-38

Rasser MW, Riegl B (2002) Holocene coral reef rubble and its binding agents. Coral Reefs 21:57-72

Rogers CS (1993) Hurricanes and coral reefs: the intermediate disturbance hypothesis revisited. Coral Reefs 12:127-137

Saigusa M (2001) Daily rhythms of emergence of small invertebrates inhabiting shallow subtidal zones: a comparative investigation at four locations in Japan. Ecol Res 16:1-28

Scoffin TP (1993) The geological effects of hurricanes on coral reefs and the interpretation of storm deposits. Coral Reefs 12:203-221

Shibuno T, Hashimoto H, Gushima K (1994) Changes with growth in feeding habits and gravel turning behavior of the wrasse, Coris gaimard. Jpn J Ichthyol 41:301-306

Takada Y (1999) Influence of shade and number of boulder layers on mobile organisms on a warm temperate boulder shore. Mar Ecol Prog Ser 189:171-179

Takada Y, Abe O (2002) Local variations in shoot density, shoot morphology, and bite mark frequency of subtropical seagrasses in Japan. Bull Fish Res Agency 4:1-10 (also available at http://www.fra.affrc.go.jp/english/bull/ 04eng.html)

Takada Y, Abe O, Nagao M, Suzuki A, Kobayashi M, Oi R, Hashimoto K, Shibuno T (2005) Seasonal variation of turbidity in a fringing reef water in Urasoko Bay, Ishigaki Island: re-suspension due to northerly winds. Galaxea 7: 37-48 (in Japanese with English abstract)

Wahl M (2001) Small scale variability of benthic assemblages: biogenic neighborhood effects. J Exp Mar Biol Ecol 258: 101-114

Yamano H, Kayanne H, Yonekura N, Kudo K (2000) 21-year changes of backreef coral distribution: causes and significance. J Coast Res 16:99-110

Submitted: July 14, 2006; Accepted: February 20, 2007

Proofs received from author(s): July 21, 2007 